\title{
Aplicação da ozonioterapia na odontologia: revisão integrativa
}

\author{
Application of ozone therapy in dentistry: an integrative review \\ Aplicación de la ozonoterapia en odontología: una revisión integradora
}

Helessandra Matias da Silva', Eduarda Carolinne Mendonça Oliveira1, Lilian Maria Santos Silva de Lira1, Lidianne Mércia Barbosa Malta Rocha1 ${ }^{1}$, Angélica Patricia León Gaines ${ }^{2}$, Ricardo Rômulo Batista Marinho ${ }^{1}$, Ellen Karla Nobre dos Santos Lima ${ }^{1 *}$.

\section{RESUMO}

Objetivo: Revisar o uso da ozonioterapia na Odontologia para divulgar as aplicações clínicas atuais e incentivar pesquisas científicas sobre o tema. Métodos: A revisão integrativa da literatura foi realizada em artigos disponíveis nas bases de dados online da Biblioteca Virtual em Saúde (BVS) e PubMed, publicados até fevereiro de 2021. Os descritores utilizados foram ozônio, ozonioterapia, saúde e Odontologia em combinação através das estratégias "ozônio AND ozonioterapia AND saúde AND odontologia" e "ozônio AND Odontologia". Foram incluídos artigos publicados em texto completo (free full text), de 2016 a 2021, nos idiomas português e inglês. Resultados: A ozonioterapia é utilizada na Odontologia como coadjuvante no controle de biofilmes e da dor pós-cirúrgica; no tratamento de cárie dentária, hipersensibilidadedentinária, líquen plano oral, gengivite, periodontite, osteomielite, osteonecrose, halitose e distúrbio da articulação temporomandibular (DTM); bem como na cicatrização de feridas; no tratamento endodôntico e no clareamento dentário. Considerações finais: A ozonioterapia reafirma-se como uma abordagem preventiva e terapêutica promissora com ampla aplicação na Odontologia. Ressalta-se a importância da continuidade de estudos de aplicabilidade e eficácia do ozônio, incluindo sua interferência no microbioma oral e na homeostase sistêmica.

Palavras-Chave: Ozônio, Ozonioterapia, Saúde, Odontologia.

\begin{abstract}
Objective: Review the use of ozone therapy in Dentistry to publicize current clinical applications and encourage scientific research on the subject. Methods: The integrative review was carried out on articles published until February 2021 which were available in the Biblioteca Virtual em Saúde (BVS) online database and the PubMed online database. The uniterms ozone, ozone therapy, health and Dentistry were used in combination through the "ozone AND ozone therapy AND health AND Dentistry" and "ozone AND Dentistry" strategies. Articles published in free full text from 2016 to 2021, in Portuguese and in English, were included. Results: Ozone therapy is used in Dentistry as an adjunct in the control of biofilms and post-surgical pain; in the treatment of dental caries, dentin hypersensitivity, oral lichen planus, gingivitis, periodontitis, osteomyelitis, osteonecrosis, halitosis, and temporomandibular joint disorder; as well as in wound healing; in endodontic treatment and tooth whitening. Final considerations: Ozone therapy is reaffirming itself as a promising preventive and therapeutic approach with wide application in Dentistry. The importance of continuing studies on the applicability and effectiveness of ozone is emphasized, including to understand its interference with the oral microbiome and systemic homeostasis.
\end{abstract}

Keywords: Ozone, Ozone therapy, Health, Dentistry.

\section{RESUMEN}

Objetivo: Repasa el uso de la ozonoterapia en Odontología, para divulgar las aplicaciones clínicas actuales y fomentar la investigación científica sobre el tema. Métodos: La revisión integradora de la literatura se realizó sobre los artículos disponibles en las bases de datos en línea de la Biblioteca Virtual en Salud (BVS) y PubMed, publicados hasta febrero de 2021. Los descriptores utilizados fueron ozono, ozonoterapia, salud y odontología en combinación a través de las estrategias "ozono AND ozonoterapia AND salud AND odontología" y "ozono AND odontología". Se incluyeron artículos publicados en texto completo (free full text) de 2016 a 2021, en portugués e inglés. Resultados: La ozonoterapia se utiliza en Odontología como coadyuvante en el control de biofilms y dolor posquirúrgico, en el tratamiento de caries dental, hipersensibilidad dentinal, liquen plano oral, gingivitis, periodontitis, osteomielitis, osteonecrosis, halitosis y trastorno de la articulación temporomandibular (ATM); así como en la cicatrización de heridas; en el tratamiento de endodoncia y en el blanqueamiento dental. Consideraciones finales: La ozonoterapia se reafirma como un enfoque preventivo y terapéutico prometedor con amplia aplicación en Odontología. Destacamos la importancia de continuar los estudios sobre la aplicabilidad y eficacia del ozono, incluida su interferencia en el microbioma oral y la homeostasis sistémica.

Palabras clave: Ozono, Ozonoterapia, Salud, Odontología.

${ }^{1}$ Centro Universitário Mario Pontes Jucá, Maceió - AL. *E-mail: ellen.nobre@umj.edu.br

2 Fundación Universitaria San Martín (FUSM), Bogotá, Colômbia.

SUBMETIDO EM: 8/2021 


\section{INTRODUÇÃO}

O ozônio (O3) é uma substância química formada através de reações fotoquímicas exotérmicas a partir de moléculas de oxigênio $(\mathrm{O} 2)$ encontradas na atmosfera. É um gás solúvel em água e possui propriedades antimicrobianas por ser oxidante. Possui um odor desagradável e é proibido armazená-lo, devendo ser utilizado de imediato, sendo o oxigênio um subproduto (ELVIS AM e EKTA JS, 2011; ASSOCIAÇÃO BRASILEIRA DE OZONIOTERAPIA (ABOZ), 2017).

O O3 é instável, ou seja, retorna à forma molecular de oxigênio com relativa facilidade. Apresenta-se como gás incolor, com odor rapidamente detectável, em concentrações baixas (0,02 a 0,05 ppm). Torna-se azulado quando em altas concentrações e, com o aumento da temperatura, a solubilidade em água e a estabilidade são reduzidas (COELHO CCS, et al., 2015).

O O3 é formado naturalmente na atmosfera através do bombardeamento do oxigênio pelos raios ultravioleta e por descargas elétricas que ocorrem quando chove. A poluição atmosférica também gera O3, pois o $\mathrm{O} 3$ é um poluente secundário formado por reações fotoquímicas entre os compostos orgânicos voláteis (COV) emitidos por veículos e indústrias; radicais hidroxila e óxido nitroso (NOx) (BRITO J, et al., 2011).

A utilização do $\mathrm{O} 3$ na área da saúde é denominada ozonioterapia, um procedimento terapêutico alternativo. No meio acadêmico, a ozonioterapia é relevante pois é necessário estudar cada aspecto em relação as suas aplicações, respeitando as concentrações e a segurança do profissional e do paciente. Além disso, é fundamental incentivar pesquisas cientificas sobre a temática em busca de novas aplicações (ABOZ, 2017; SEN S e SEN S, 2020).

Tanto quanto demonstrado para outros gases medicinais usados na prática clínica (O2, NO e CO), o ozônio pode ser tóxico ou seguro como uma droga real, dependendo de sua dosagem, tempo de exposição e capacidade antioxidante do tecido exposto. Com base nas implicações farmacológicas e evidências clínicas, observa-se que o uso de ozônio medicinal pode ser vantajoso no tratamento de várias doenças. No entanto, são necessárias orientações precisas e concentrações não tóxicas em aplicações terapêuticas (DI MAURO $R$, et al., 2019).

A Organização Mundial da Saúde (OMS) recomenda a incorporação de procedimentos medicinais tradicionais nos sistemas nacionais de saúde. O Ministério da Saúde do Brasil denomina tais procedimentos como Práticas Integrativas e Complementares (PICs). Em consonância, diversas categorias profissionais de saúde no país reconhecem as PICs como abordagem do cuidado e a ozonioterapia foi agregada ao Sistema Único de Saúde (SUS) como uma PIC, sendo oferecida gratuitamente à população (MINISTÉRIO DA SAÚDE (MS), 2018).

De acordo com a Portaria do Ministério da Saúde n 702, de 21 de março de 2018, a ozonioterapia é uma PIC segura e de baixo custo. A aplicação da mistura dos gases oxigênio e ozônio com finalidade terapêutica é utilizada em outros países (e. g. Itália, Alemanha, Espanha, Portugal, Rússia, Cuba e China) e tal ozônio medicinal induz o estresse oxidativo controlado e moderado quando administrado em doses terapêuticas precisas, o que contribui com o tratamento de patologias variadas (MS, 2018).

No contexto pandêmico mundial, a ozonioterapia tem sido testada no tratamento de indivíduos com COVID-19 que apresentam síndrome respiratória aguda, podendo favorecer a evolução para a cura e podendo atenuar a produção desregulada de citocinas inflamatórias, a chamada "tempestade de citocinas" (FRANZINI M, et al., 2020; VALDENASSI L, et al., 2020; MARINI S, et al., 2020; TASCINI C, et al., 2021).

$\mathrm{Na}$ Odontologia, a ozonioterapia auxilia o tratamendo de cárie, infecção endodôntica e doenças periodontais, apresentado-se como coadjuvante na prática clínica (SEN S e SEN S, 2020; BIBLIOTECA REGIONAL DE MEDICINA (BIREME), 2020). Contudo, existem novas possibilidades de utilização da ozonioterapia na Odontologia? Dessa forma, o presente trabalho objetiva realizar uma revisão integrativa da literatura atual sobre a aplicação da ozonioterapia na Odontologia.

\section{MÉTODOS}

A revisão integrativa da literatura foi realizada em artigos disponíveis nas bases de dados online Biblioteca Virtual em Saúde (BVS) e PubMed até fevereiro de 2021. A BVS inclui as bases Bibliografia Brasileira de 
Odontologia (BBO), Scientific Electronic Library Online (SciELO), Literatura Latino-Americana e do Caribe em Ciências da Saúde (LILACS), MEDLINE e Cochrane.

Considerando os indexadores presentes no Descritores em Ciências da Saúde (DECS) e no Medical Subject Headings (MESH), os descritores utilizados para a busca foram: ozônio (DECS / MESH), ozonioterapia, saúde (DECS / MESH) e Odontologia (DECS / MESH) em duas estratégias de busca, nos idiomas português e inglês: "ozônio AND ozonioterapia AND saúde AND Odontologia" e "ozônio AND Odontologia". O período de busca foi de dezembro de 2020 a fevereiro de 2021.

Foram avaliados artigos disponíveis em texto completo (free full text), de 2016 a 2021, nos idiomas português e inglês. Os artigos foram selecionados através do título e do resumo por dois avaliadores e o terceiro avaliador revisou criticamente a seleção / inclusão no estudo. Os critérios de inclusão foram: texto completo disponível, data da publicação de 2016 a 2021 e idioma do texto português ou inglês.

Os artigos selecionados foram analisados na integra pelos três avaliadores e foram incluídos no estudo quando relacionados à aplicação da ozonioterapia na Odontologia. Os critérios de exclusão foram: artigo duplicado e artigo fora da temática "ozonioterapia na Odontologia".

\section{RESULTADOS}

O detalhamento e os resultados das etapas da revisão integrativa foram organizados no Quadro 1. A combinação dos descritores utilizados na busca dos artigos nas bases de dados online foi exposta no Quadro 2.

Quadro 1 - Detalhamento das etapas da revisão integrativa com resultados obtidos.

\begin{tabular}{|c|c|c|}
\hline Etapa & Detalhamento & Resultados \\
\hline \multirow{6}{*}{$1^{\underline{a}}$} & Tema & Ozonioterapia na Odontologia \\
\hline & Pergunta norteadora & $\begin{array}{l}\text { Existem novas possibilidades de utilização da } \\
\text { ozonioterapia na Odontologia? }\end{array}$ \\
\hline & Objetivo & $\begin{array}{l}\text { Realizar uma revisão integrativa da literatura sobre a } \\
\text { aplicação da ozonioterapia na Odontologia }\end{array}$ \\
\hline & Estratégia de Busca & $\begin{array}{l}\text { 1. "Ozônio AND ozonioterapia AND saúde AND } \\
\text { Odontologia" } \\
\text { 2. "ozônio AND Odontologia" }\end{array}$ \\
\hline & $\begin{array}{l}\text { Descritores estruturados no DECS / } \\
\text { MESH }\end{array}$ & $\begin{array}{l}\text { Ozônio. Saúde. Odontologia (DECS) } \\
\text { Ozone. Health. Dentistry (MESH) }\end{array}$ \\
\hline & Bibliotecas Virtuais & $\begin{array}{l}\text { 1. Biblioteca Virtual em Saúde (BVS) (inclui as bases } \\
\text { BBO, SciELO, LILACS, MEDLINE, Cochrane) } \\
\text { 2. PubMed }\end{array}$ \\
\hline \multirow{3}{*}{$2^{\underline{a}}$} & Período de coleta dos dados & Dezembro de 2020 a fevereiro de 2021 \\
\hline & Critérios de inclusão & $\begin{array}{l}\text { 1. Texto completo disponível } \\
\text { 2. Data da publicação ( } 2016-2021) \\
\text { 3. Idioma português ou inglês }\end{array}$ \\
\hline & Critérios de exclusão & $\begin{array}{l}\text { 1. Artigo duplicado } \\
\text { 2. Artigo em outra temática }\end{array}$ \\
\hline $3^{\mathrm{a}}$ & $\begin{array}{l}\text { Número de trabalhos selecionados para } \\
\text { revisão a partir da leitura dos agentes } \\
\text { indexadores das publicações (título e } \\
\text { resumo) }\end{array}$ & 10 trabalhos \\
\hline $4^{\mathrm{a}}$ & $\begin{array}{l}\text { Categorias obtidas com a análise dos } \\
\text { trabalhos científicos investigados }\end{array}$ & $\begin{array}{l}\text { Ensaio clínico controlado randomizado (04) } \\
\text { Estudo in vivo (02) } \\
\text { Coorte }(01) \\
\text { Revisão sistemática da literatura (01) } \\
\text { Revisão integrativa da literatura (01) } \\
\text { Revisão narrativa da literatura (01) }\end{array}$ \\
\hline $5^{\mathrm{a}}$ & $\begin{array}{l}\text { Análise, interpretação e discussão dos } \\
\text { resultados }\end{array}$ & $\begin{array}{l}\text { Os resultados desta etapa estão presentes nas seções } \\
\text { resultados e discussão do presente trabalho. }\end{array}$ \\
\hline
\end{tabular}

Fonte: Silva HM, et al., 2021. 
Quadro 2 - Combinação dos descritores utilizados na busca sistemática e artigos resultantes.

\begin{tabular}{|c|c|c|c|c|}
\hline $\begin{array}{c}\text { Base de } \\
\text { dados }\end{array}$ & Estratégias de busca & $\begin{array}{c}\text { Artigos } \\
\text { encontrados }\end{array}$ & $\begin{array}{c}\text { Artigos } \\
\text { selecionados para } \\
\text { avaliação }\end{array}$ & $\begin{array}{c}\text { Artigos } \\
\text { incluídos no } \\
\text { trabalho }\end{array}$ \\
\hline $\begin{array}{c}\text { BVS } \\
(2016-2021)\end{array}$ & $\begin{array}{c}\text { ozônio AND ozonioterapia AND } \\
\text { saúde AND Odontologia }\end{array}$ & 1 & 1 & 1 \\
\cline { 2 - 5 } & ozônio AND Odontologia & 3 & 3 & 3 \\
\hline $\begin{array}{c}\text { PubMed } \\
(2016-2021)\end{array}$ & $\begin{array}{c}\text { ozone AND ozone therapy AND } \\
\text { health } \\
\text { AND Dentistry }\end{array}$ & 10 & 7 & 7 \\
\hline
\end{tabular}

Fonte: Silva HM, et al., 2021.

A Figura 1 representa um fluxograma com processo de inclusão e exclusão dos trabalhos avaliados na presente revisão. Os 10 trabalhos selecionados foram incluídos por trazerem informações relativas à aplicação da ozonioterapia na Odontologia. As principais informações das publicações incluídas foram organizadas no Quadro 3. Em seguida, a distribuição dos artigos incluídos por ano de publicação foi representada no Gráfico 1.

Figura 1 - Fluxo da revisão integrativa da literatura científica

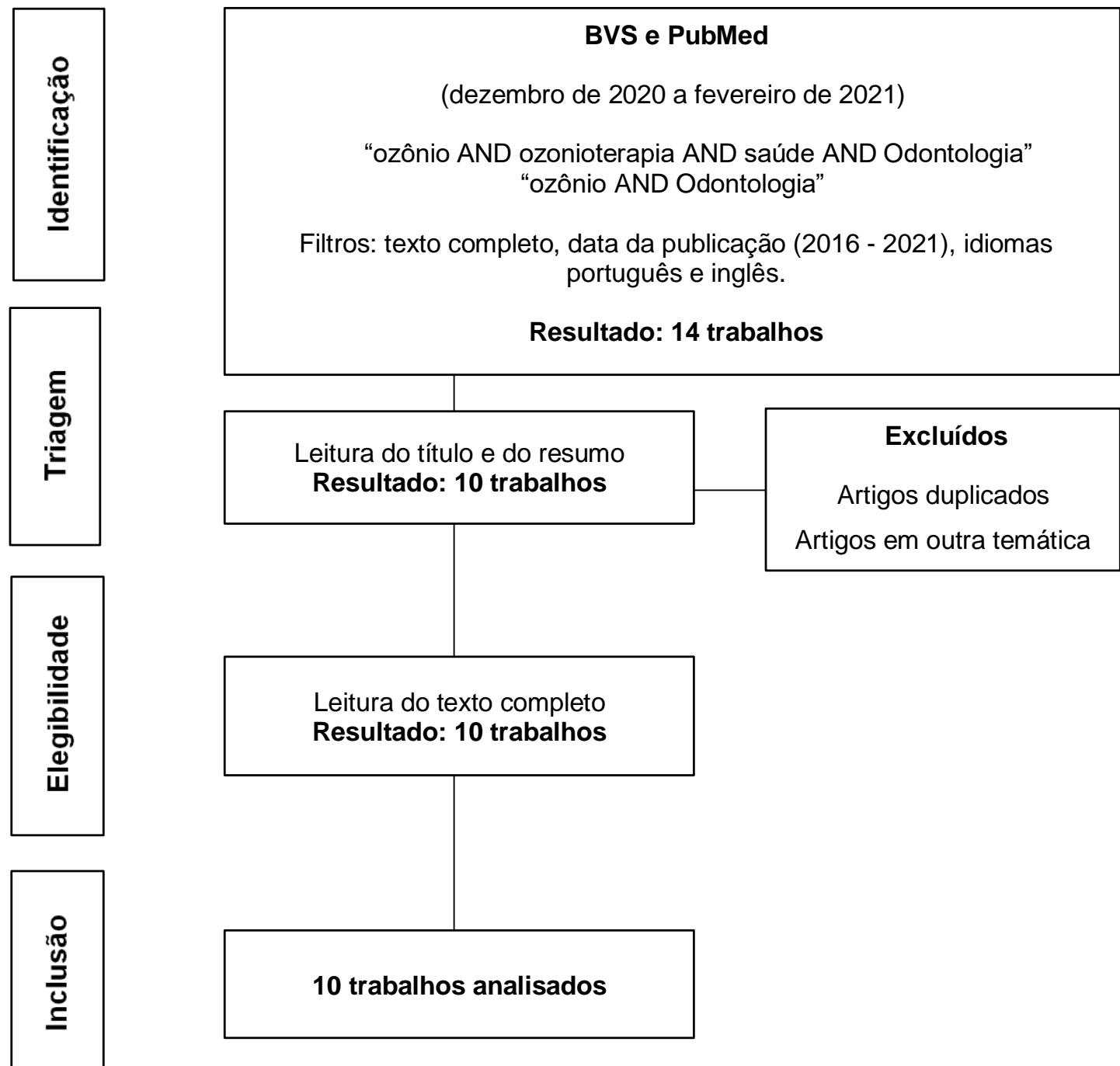

Fonte: Silva HM, et al., 2021. 
Quadro 3 - Publicações incluídas no estudo

\begin{tabular}{|c|c|c|c|}
\hline Título & $\begin{array}{l}\text { Autor } \\
\text { (ano) }\end{array}$ & Objetivo & Tipo de estudo \\
\hline $\begin{array}{c}\text { Tratamento com ozônio de } \\
\text { estomatite aftosa recorrente: um } \\
\text { estudo duplo-cego }\end{array}$ & $\begin{array}{l}\text { Al-Omiri } \\
\text { MK, et al. } \\
(2016)\end{array}$ & $\begin{array}{c}\text { Avaliar o uso do ozônio no } \\
\text { tratamento da estomatite aftosa } \\
\text { recorrente. }\end{array}$ & Coorte \\
\hline $\begin{array}{c}\text { Eficácia de branqueamento de } \\
\text { ozônio / peróxido de hidrogênio } \\
\text { versus aplicação de peróxido de } \\
\text { hidrogênio / ozônio }\end{array}$ & $\begin{array}{l}\text { Al-Omiri } \\
\text { MK, et al. } \\
(2017)\end{array}$ & $\begin{array}{l}\text { Comparar a eficácia do } \\
\text { clareamento dental após o uso de } \\
\text { ozônio, antes e após a aplicação } \\
\text { de peróxido de hidrogênio (H2O2) }\end{array}$ & $\begin{array}{l}\text { Ensaio clínico } \\
\text { controlado } \\
\text { randomizado }\end{array}$ \\
\hline $\begin{array}{c}\text { Ensaio clínico controlado } \\
\text { randomizado sobre a } \\
\text { sensibilidade ao clareamento e a } \\
\text { eficácia do peróxido de hidrogênio } \\
\text { em comparação com as } \\
\text { combinações de peróxido de } \\
\text { hidrogênio e ozônio }\end{array}$ & $\begin{array}{l}\text { Al-Omiri } \\
\text { MK, et al. } \\
(2018)\end{array}$ & $\begin{array}{l}\text { Comparar a eficácia clínica em } \\
\text { relação à sensibilidade ao } \\
\text { clareamento e ao clareamento da } \\
\text { cor do dente usando um gel } \\
\text { clareador de peróxido de } \\
\text { hidrogênio (H2O2) com o uso } \\
\text { adicional de ozônio antes ou depois } \\
\text { da aplicação de H2O2. }\end{array}$ & $\begin{array}{l}\text { Ensaio clínico } \\
\text { controlado } \\
\text { randomizado }\end{array}$ \\
\hline $\begin{array}{l}\text { Efeito da ozonioterapia tópica na } \\
\text { cicatrização de feridas gengivais } \\
\text { em porcos: análise histológica e } \\
\text { imuno-histoquímica }\end{array}$ & $\begin{array}{l}\text { Eroglu ZT, } \\
\text { et al. } \\
\text { (2018) }\end{array}$ & $\begin{array}{c}\text { Avaliar os efeitos da ozonioterapia } \\
\text { na cicatrização secundária de } \\
\text { feridas. }\end{array}$ & Estudo in vivo \\
\hline $\begin{array}{c}\text { Utilidade clínica da terapia com } \\
\text { ozônio em medicina dentária e } \\
\text { oral }\end{array}$ & $\begin{array}{l}\text { Suh Y, et } \\
\text { al. (2019) }\end{array}$ & $\begin{array}{c}\text { Revisar história, composição e uso } \\
\text { do ozônio em todo o mundo na } \\
\text { odontologia. }\end{array}$ & $\begin{array}{l}\text { Revisão } \\
\text { narrativa da } \\
\text { literatura }\end{array}$ \\
\hline $\begin{array}{l}\text { Avaliação do efeito da aplicação } \\
\text { tópica e sistêmica de ozônio na } \\
\text { periodontite: um estudo } \\
\text { experimental em ratos }\end{array}$ & $\begin{array}{l}\text { Saglam E, } \\
\text { et al. } \\
\text { (2019) }\end{array}$ & $\begin{array}{c}\text { Determinar o efeito da aplicação } \\
\text { sistêmica e tópica de ozônio na } \\
\text { perda óssea alveolar. }\end{array}$ & Estudo in vivo \\
\hline $\begin{array}{c}\text { Aplicabilidade da ozonioterapia na } \\
\text { odontologia: uma revisão de } \\
\text { literatura }\end{array}$ & $\begin{array}{l}\text { Prestes } \\
\text { LV, et al. } \\
(2020)\end{array}$ & $\begin{array}{l}\text { Ressaltar as aplicabilidades } \\
\text { do ozônio na área odontológica, } \\
\text { explicitando meios de utilização, } \\
\text { suas respectivas ações e } \\
\text { as contraindicações. }\end{array}$ & $\begin{array}{l}\text { Revisão } \\
\text { sistemáica da } \\
\text { literatura }\end{array}$ \\
\hline $\begin{array}{l}\text { Terapia de ozônio, uma nova } \\
\text { perspectiva em odontologia: } \\
\text { revisão integrativa }\end{array}$ & $\begin{array}{l}\text { Sen S e } \\
\text { Sen S } \\
(2020)\end{array}$ & $\begin{array}{l}\text { Enfatizar a utilidade do ozônio na } \\
\text { gestão de saúde bucal. Revisar o } \\
\text { potencial terapêutico e a aplicação } \\
\text { clínica em patologias orais, } \\
\text { periodontia, endodontia, cirurgia } \\
\text { oral, prótese dentária, ortodontia, } \\
\text { odontologia restauradora, } \\
\text { cicatrização de feridas, } \\
\text { mineralização dentária. }\end{array}$ & $\begin{array}{l}\text { Revisão } \\
\text { integrativa da } \\
\text { literatura }\end{array}$ \\
\hline $\begin{array}{l}\text { Avaliação da metaloproteinase de } \\
\text { matriz (MMP-8) salivar em } \\
\text { pacientes periodontais } \\
\text { submetidos à terapia periodontal } \\
\text { não cirúrgica e enxaguatório bucal } \\
\text { com base no azeite de oliva } \\
\text { ozonizado: um ensaio clínico } \\
\text { randomizado. }\end{array}$ & $\begin{array}{l}\text { Nardi GM, } \\
\text { et al. } \\
(2020)\end{array}$ & $\begin{array}{c}\text { Avaliar em uma coorte de } \\
\text { pacientes com diagnóstico de } \\
\text { periodontite a eficácia da terapia } \\
\text { periodontal não cirúrgica auxiliada } \\
\text { pelo uso de enxaguatório bucal à } \\
\text { base de azeite de oliva ozonizado. }\end{array}$ & $\begin{array}{l}\text { Ensaio clínico } \\
\text { randomizado }\end{array}$ \\
\hline $\begin{array}{l}\text { Influência da água ozonizada na } \\
\text { dor, edema e trismo durante a } \\
\text { cirurgia do terceiro molar } \\
\text { impactado: um ensaio clínico } \\
\text { randomizado triplo-cego. }\end{array}$ & $\begin{array}{l}\text { Glória } \\
\text { JCR, et al. } \\
(2020)\end{array}$ & $\begin{array}{c}\text { Avaliar a eficácia da água } \\
\text { ozonizada na dor, edema e trismo } \\
\text { após cirurgias de terceiros molares } \\
\text { mandibulares impactados quando } \\
\text { comparada à água bidestilada. }\end{array}$ & $\begin{array}{l}\text { Ensaio clínico } \\
\text { randomizado }\end{array}$ \\
\hline
\end{tabular}

Fonte: Silva HM, et al., 2021. 
Gráfico 1 - Distribuição dos artigos incluídos no estudo por ano de publicação.

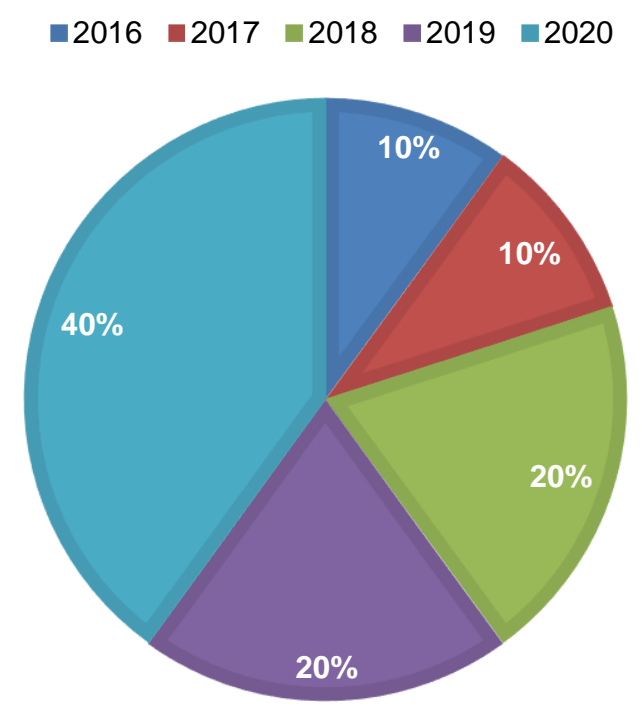

Fonte: Silva HM, et al., 2021.

Os estudos realizados em humanos ( 1 coorte e 4 ensaios clínicos controlados randomizados) foram publicados de 2016 a 2020 e os principais achados foram resumidos a seguir em ordem cronológica (ALOMIRI MK, et al., 2016; 2017; 2018; NARDI GM, et al., 2020; GLÓRIA JCR, et al., 2020).

De acordo com Al-Omiri MK, et al. (2016), a aplicação de ozônio nas lesões de estomatite aftosa recorrente, por 60 segundos, reduziu os níveis de dor e promoveu a cicatrização das úlceras, reduzindo o tamanho e a duração das lesões.

O clareamento combinando ozônio e $\mathrm{H} 2 \mathrm{O} 2$ produziu melhores tons de dente do que o clareamento apenas com H2O2; o branqueamento com 38\% de $\mathrm{H} 2 \mathrm{O} 2$ por 20 minutos (combinado com ozônio por 60 segundos) produziu resultados semelhantes, independentemente da aplicação do ozônio antes ou depois do H2O2 (ALOMIRI MK, et al., 2017). A aplicação de ozônio após $\mathrm{H} 2 \mathrm{O} 2$ foi preferível em relação à sensibilidade ao clareamento, quando avaliado em ensaio clínico controlado randomizado (AL-OMIRI MK, et al., 2018).

Raspagem e alisamento radicular com auxílio de enxaguatório bucal com azeite de oliva ozonizado foram mais eficazes na redução de MMP-8 salivar do que apenas raspagem e alisamento radicular (NARDI GM, et al., 2020).

Como método de irrigação, a água ozonizada foi compatível com a água bidestilada e teve efeitos satisfatórios no manejo da dor, edema e trismo após a remoção cirúrgica do terceiro molar (GLÓRIA JCR, et al., 2020).

Além disso, em estudos experimentais in vivo, ao se avaliar o efeito da ozonioterapia tópica na cicatrização de feridas gengivais em porcos, observou-se que a aplicação tópica de gás ozônio pode ser eficaz nos estágios iniciais da cicatrização secundária de feridas orais (EROGLU ZT, et al., 2018). E, na avaliação do efeito da aplicação tópica e sistêmica de ozônio na periodontite em ratos, observou-se que a aplicação de ozônio sistêmico foi mais eficaz na redução da perda óssea alveolar (SAGLAM E, et al., 2019).

Os estudos de revisão da literatura foram publicados em 2019 e 2020 (SUH Y, et al., 2019; PRESTES LV, et al., 2020; SEN S e SEN S, 2020). Segundo Sen S e Sen S (2020), o ozônio é uma forma de oxigênio que tem papel efetivo no manejo das doenças bucais; a aplicação do ozônio na higiene bucal surge como uma modalidade de tratamento nova e alternativa na Odontologia; bem como o impacto da informação biológica e digital leva à aplicação de ozônio por diferentes meios para inúmeras opções de tratamento na cavidade oral.

A ozonioterapia tem se mostrado efetiva e segura em diversas práticas odontológicas (PRESTES LV, et al., 2020). A ozonioterapia tem sido usada em controle de biofilmes, canais radiculares, cicatrização de 
feridas, cárie dentária, líquen plano oral, gengivite, periodontite, halitose, osteonecrose da mandíbula, dor pós-cirúrgica, hipersensibilidade dentinária, distúrbio da articulação temporomandibular e clareamento dentário (SUH Y, et al., 2019).

\section{DISCUSSÃO}

O uso terapêutico do ozônio iniciou com Werner von Siemens, em 1857, ao produzir e patentear o primeiro gerador de ozônio, utilizando a descarga de corona ou silenciosa como fonte elétrica, o que era o padrão para os equipamentos. No Brasil, em 1975, há relato do primeiro uso do ozônio na área médica, porém a ozonioterapia foi reconhecida pelo Conselho Federal de Odontologia (CFO) em 2015, podendo ser exercida pelos profissionais que possuam habilitação em ozonioterapia na área odontológica (CFO, 2015; ABOZ, 2017). Dessa forma, a presente revisão integrativa analisou trabalhos publicados após o reconhecimento da ozonioterapia pelo CFO, a partir de 2016. Observou-se um aumento no número de trabalhos publicados de 2016 a 2020.

Trabalhos anteriormente publicados (1996, 2004, 2006, 2008 e 2009) são aqui citados no contexto histórico deste tema, visto que as aplicações da ozonioterapia vêm evoluindo ao longo dos anos. Por exemplo, em 1996, Escarpanter Bulies JC já afirmava que o ozônio produz oxidação em microrganismos, tornando-se bactericida, fungicida e parasiticida. Contudo, apenas em 2018, a ozonioterapia foi agregada ao Sistema Único de Saúde brasileiro como uma Prática Integrativa e Complementar, oferecendo-se o tratamento de forma gratuita (MS, 2018). Porém, ainda em 2018, o Conselho Federal de Medicina ressaltou que a ozonioterapia só pode ser utilizada na medicina de forma experimental (CONSELHO FEDERAL DE MEDICINA (CFM), 2018).

Existem várias ações conhecidas do ozônio no corpo humano, como a ação antimicrobiana, imunoestimulante, antihipóxica, analgésica, desintoxicante, bioenergética e biossintética. A ação antimicrobiana ocorre como resultado da atuação nas células, danificando a membrana citoplasmática devido à ozonólise das ligações duplas. Esta ação é inespecífica e seletiva às células microbianas; não danificando as células do corpo humano devido a sua capacidade antioxidante. Dessa forma, a ozonioterapia é particularmente útil em cepas resistentes a antibióticos (SEIDLER V, et al., 2008; ABOZ, 2017).

A ação imunoestimulante influencia o sistema imunológico celular e humoral. A ozonioterapia estimula a síntese de imunoglobulinas, ativa a função dos macrófagos e aumenta a sensibilidade dos microrganismos à fagocitose. Quando o ozônio é administrado em baixas concentrações, a imunidade do organismo humano é mobilizada, isto é, o ozônio estimula o sistema imunológico e as células respondem a este estímulo produzindo mais citocinas. Tais moléculas, por sua vez, ativam outras células imunológicas, desencadeando uma cascata de sinais em todo o sistema imunológico, que é preparado para combater invasores. Isso significa que a aplicação de ozônio medicinal é útil para a ativação imunológica em pacientes com estado imunológico deficiente (SEIDLER V, et al., 2008, NARDI GM, et al., 2020).

Em sua ação antihipóxica, o ozônio provoca o aumento do oxigênio dissolvido no sangue (pO2) nos tecidos e melhora o transporte de oxigênio no sangue, o que resulta em alteração do metabolismo celular, ativação de processos aeróbicos (glicólise, ciclo de Krebs, $\beta$-oxidação de ácidos graxos) e utilização de recursos energéticos. Sua capacidade de estimular a circulação sanguínea é utilizada no tratamento de distúrbios circulatórios e o torna valioso nas funções orgânicas revitalizantes (SEIDLER V, et al., 2008).

Quanto às ações analgésica e desintoxicante, o ozônio causa secreção de vasodilatadores que são responsáveis pela dilatação das arteríolas e vênulas. Já em relação às ações bioenergética e biossintética, 0 ozônio ativa mecanismos de síntese proteica, aumentando a quantidade de ribossomos e mitocôndrias nas células. Essas mudanças no nível celular explicam a elevação da atividade funcional e no potencial de regeneração de tecidos e órgãos (SEIDLER V, et al., 2008; EROGLU ZT, et al., 2018; PCHEPIORKA R, et al., 2020).

$\mathrm{Na}$ Odontologia, a ozonioterapia tem sido aplicada como adjuvante terapêutico em doenças agudas e crônicas. O ozônio é utilizado em baixas concentrações e, por isso, pode ser considerado um tratamento seguro ao ser utilizado corretamente por profissional habilitado (PRESTES LV, et al., 2020). 
O óleo ozonizado é um composto em que se mistura o gás 03 com azeite, tornando-se mais estável e podendo ser usado no tratamento de infecções e fístulas. Para obter o óleo ozonizado, é necessário o borbulhar o azeite com o gás 03 , continuamente, durante 2 dias, gerando uma série de compostos químicos que são chamados ozonídeos e peróxidos, os quais possuem ação antimicrobiana e atuam no sistema imune, inclusive diminuindo a produção local da enzima degradadora de colágeno MMP-8 (BOCCI VA, 2004; NARDI GM, et al., 2020).

A utilização do óleo / azeite ozonizado de forma tópica acelerou a cicatrização de feridas agudas cutâneas, pois promoveu a síntese de colágeno e a proliferação de fibroblastos (STUBINGER S, et al., 2006). Bem como promoveu a diminuição local da colagenase MMP-8 (NARDI GM, et al., 2020). A cicatrização tecidual foi verificada na terapia com gás ozônio, a qual foi eficaz em melhorar a angiogênese e a contagem de fibroblastos na mucosa bucal de ratos durante a cicatrização de feridas provocadas experimentalmente (PCHEPIORKA R, et al., 2020). Já a água ozonizada foi compatível com a água bidestilada como método de irrigação após a remoção cirúrgica do terceiro molar e teve efeitos satisfatórios no manejo da dor, edema e trismo (GLÓRIA JCR, et al., 2020).

Shekhar A, et al. (2021) avaliaram o efeito da terapia com ozônio na inflamação, dor e cicatrização de feridas após cirurgia de implante. Observaram que a terapia com ozônio acelerou a cicatrização, minimizou a inflamação do tecido e diminuiu a dor. A osteotomia foi realizada com irrigação salina no grupo controle e, no grupo experimental, a irrigação foi feita com água ozonizada na concentração de $25 \mu \mathrm{g} / \mathrm{mL}$, juntamente com gás ozônio. A avaliação foi feita dosando a proteína $C$ reativa para a inflamação, usando Escala Visual Analógica para a dor e índice de cura de feridas para a cicatrização tecidual.

A ozonioterapia mostrou-se superior a técnicas convencionais quanto à capacidade de neutralização ou inibição do crescimento bacteriano na cavidade oral (SILVA PM e DIETRICH L, 2018). Por isso, a aplicação tópica do $\mathrm{O} 3$ pode ser eficaz na cicatrização de lesões orais causadas por vírus (e.g. Herpesvírus humano) e fungos (e.g. Candida albicans) que foram agravadas pela infecção por bactérias (AL-OMIRI MK, et al., 2016; EROGLU ZT, et al., 2018).

O efeito antimicrobiano da água ozonizada nas bactérias que invadem os túbulos dentinários foi observado, anteriormente, por Nagayoshi M, et al. (2004). Portanto, na Endodontia, a maioria dos estudos concentrou-se no ozônio como agente irrigante e como medicação intracanal, visto que o tratamento endodôntico visa eliminar os microrganismos existentes no sistema de canais radiculares antes da obturação endodôntica. Atualmente, a aplicação do ozônio na terapêutica do sistema de canais representa um tratamento biológico, indolor ao paciente, capaz de melhorar a assepsia dos canais e considerado coadjuvante ao tratamento convencional, com ação antimicrobiana e biocompatibilidade (ALMEIDA KO, et al., 2019).

Fernandes KGC, et al. (2021) destacaram que o ozônio é capaz de inativar microrganismos por meio da oxidação direta de seus componentes estruturais, podendo ser proposto como coadjuvante em tratamentos endodônticos contra bactérias Gram-positivas e Gram-negativas presentes na cavidade oral e canais radiculares. Porém, são necessários ensaios clínicos controlados e randomizados para comprovar sua eficácia e dosimetria em tratamentos endodônticos.

$\mathrm{Na}$ Periodontia, o ozônio atua como bactericida e estimulador do processo de reparo, podendo ser empregado no tratamento de periodontite e peri-implantite, reduzindo o curso clínico dessas patologias (NOGALES CG, et al., 2009; HUTH KC, et al., 2011). Experimentalmente, a aplicação de ozônio sistêmico foi considerada mais eficaz na redução da perda óssea alveolar em ratos (SAGLAM E, et al., 2019).

No contexto da Estética Orofacial, o clareamento combinando ozônio e $\mathrm{H} 2 \mathrm{O} 2$ produziu melhores tons de dente do que o clareamento apenas com H2O2. O branqueamento com $38 \%$ de $\mathrm{H} 2 \mathrm{O} 2$ por 20 minutos combinado com ozônio por 60 segundos produziu resultados semelhantes, independentemente da aplicação do ozônio antes ou depois do H2O2. Em relação à sensibilidade ao clareamento, a aplicação de ozônio após o H2O2 foi preferível (AL-OMIRI MK, et al., 2017; 2018).

Assim, a ozonioterapia tem sido usada, até o momento, como adjuvante no controle do biofilme oral; na cicatrização de feridas; no tratamento de cárie dentária e canais radiculares; no controle de líquen plano oral, 
gengivite, periodontite, halitose, hipersensibilidade dentinária, distúrbio da articulação temporomandibular; no tratamento da osteonecrose da mandíbula e no branqueamento dentário (SUH Y, et al., 2019). A ozonioterapia pode ser útil como tratamento adjuvante na osteomielite e na osteonecrose, através do estímulo vascular, imunológico, reparador e bactericida (MARTINS Y, 2018; CARVALHO JESR, 2019).

Para Frota DLR e Ferreira MA (2020), a terapia com ozônio pôde ser usada com segurança e eficiência na Odontologia, como prática complementar de desinfecção, sem contraindicações. Dessa forma, a Organização Pan-Americana da Saúde e a Organização Mundial da Saúde (OPAS/OMS) publicaram, recentemente, um mapa de evidências indicando os procedimentos odontológicos em que a ozonioterapia mostrou-se eficaz; com efeitos positivos na redução da dor aguda na cavidade oral em pós-operatório e na redução de colônias bacterianas (BIREME, 2020).

Portanto, na busca por técnicas complementares na prática odontológica, a ozonioterapia mostrou-se efetiva e segura (PRESTES LV, et al., 2020). Seu potencial na prática clínica fundamenta-se, principalmente, em suas propriedades antimicrobiana e imunomoduladora (FRANÇA GR, et al., 2020). No entanto, observase pela escassez de estudos moleculares na literatura, que seu potencial imunomodulador precisa ser explorado para compreensão de quais vias e moléculas da resposta inflamatória são moduladas.

Dessa forma, estudar a utilização do ozônio na Odontologia ajuda os profissionais a conhecer e a desenvolver novas técnicas de tratamento para patologias orofaciais que possuem, ainda hoje, poucos recursos para um bom prognóstico, contribuindo para melhor bem-estar social (LEAL WRS, et al., 2020).

\section{CONSIDERAÇÕES FINAIS}

A ozonioterapia reafirma-se como uma abordagem preventiva e terapêutica promissora com ampla aplicação na Odontologia, podendo ser implementada na realidade do Sistema Único de Saúde brasileiro. Ressalta-se a importância da continuidade de estudos de aplicabilidade e eficácia do ozônio, incluindo sua interferência no microbioma oral e na homeostase sistêmica. Este trabalho incentiva outras pesquisas em ozonioterapia, principalmente no que diz respeito à segurança, a sua aplicabilidade e ao custo / benefício.

\section{AGRADECIMENTOS}

Os autores agradecem ao Centro Universitário Mario Pontes Jucá (UMJ, Maceió - AL) e à coordenação do curso de Odontologia (UMJ, Maceió - AL).

\section{REFERÊNCIAS}

1. ALMEIDA KO et al. Ozonioterapia: o uso de ozônio na endodontia. Revista Inovação da Aprendizagem, 2019; 1(1): 10.

2. AL-OMIRI MK, et al. Bleaching efficacy of ozone/hydrogen peroxide versus hydrogen peroxide/ozone application. Quintessence Int., 2017; 48(10): 783-791.

3. AL-OMIRI MK, et al. Ozone treatment of recurrent aphthous stomatitis: a double blinded study. Sci Rep., 2016; 6: 27772.

4. AL-OMIRI MK, et al. Randomized controlled clinical trial on bleaching sensitivity and whitening efficacy of hydrogen peroxide versus combinations of hydrogen peroxide and ozone. Sci Rep., 2018; 8(1):2407.

5. ASSOCIAÇÃO BRASILEIRA DE OZONIOTERAPIA (ABOZ). Nota de esclarecimento sobre a ozonioterapia. São Paulo, 18 de dezembro de 2017. Disponível em: https://www.aboz.org.br/noticias/nota-de-esclarecimento-sobre-aoz\%20onioterapia/74/. Acessado em: 28 de fevereiro de 2021.

6. BIBLIOTECA REGIONAL DE MEDICINA (BIREME). Efetividade Clínica da Ozonioterapia Bucal. BVS Mapa de Evidências [Online]. São Paulo: BIREME/OPAS/OMS. 2 ${ }^{a}$ edição, atualizada. Novembro 2020. Disponível em: https://public.tableau.com/profile/bireme\#!/vizhome/ozonioterapia-bucal-pt/evidence-map. Acessado em: 31 de março de 2021.

7. BOCCI VA. How Ozone acts and how it exerts therapeutic effects In: LYNCH E. Ozone: the revolution in Dentistry. Surrey: Quintessence, 2004; 5-22.

8. BRITO J, et al. Composição da atmosfera e dos precursores de ozônio em Campos Elíseos, Duque de Caxias, RJ. Revista Perspectivas da Ciência e Tecnologia, 2011; 3(1/2): 4.

9. CARVALHO JESR. Ozonioterapia como modalidade terapêutica para osteonecrose dos maxilares. Revista Brasileira de Odontologia, 2019; 76(1): 10. 
10. COELHO CCS, et al. Ozonização como tecnologia pós-colheita na conservação de frutas e hortaliças: Uma revisão. Rev. bras. eng. agríc. ambient., 2015; 19(4): 369-375.

11. CONSELHO FEDERAL DE MEDICINA (CFM). Resolução 2.181, de 20 de abril de 2018. Disponível em: https://www.in.gov.br/web/guest/materia/-/asset_publisher/Kujrw0TZC2Mb/content/id/29305235/do1-2018-07-10resolucao-2-181-de-20-de-abril-de-2018-29305206. Acessado em: 28 de fevereiro de 2021.

12. CONSELHO FEDERAL DE ODONTOLOGIA (CFO). Resolução no 166, de 24 de novembro de 2015. Disponível em: http://sintse.tse.jus.br/documentos/2015/Dez/9/para-conhecimento/resolucao-no-166-de-24-de-novembro-de-2015. Acessado em: fevereiro de 2021.

13. DI MAURO R, et al. The Biochemical and Pharmacological Properties of Ozone: The Smell of Protection in Acute and Chronic Diseases. Int J Mol Sci., 2019; 20(3): 634.

14. ELVIS AM, EKTA JS. Ozone therapy: A clinical review. J Nat Sci Biol Med., 2011; 2(1): 66-70.

15. EROGLU ZT, et al. Effect of topical ozonetherapy on gingival wound healing in pigs: histological and immunohistochemical analysis. J Appl Oral Sci., 2018.

16. ESCARPANTER BULIES JC. Una solución para exposiciones óseas postraumáticas: asociación de injerto de epiplon mayor con ozonoterapia. Rev Cubana Invest Bioméd, 1996; 15(2).

17. FERNANDES KGC, et al. Ozonioterapia como coadjuvante na irrigação do sistema de canais radiculares. Research, Society and Development, 2021; 10(1): 15.

18. FRANÇA GR, et al. Ozonioterapia e sua aplicação na odontologia: revisão de literatura. Revista Open Rit, 2020; 1(1): 15.

19. FRANZINI M, et al. Oxygen-ozone $\left(\mathrm{O}_{2}-\mathrm{O}_{3}\right)$ immunoceutical therapy for patients with COVID-19. Preliminary evidence reported. Int Immunopharmacol., 2020; 88: 106879.

20. FROTA DLR, FERREIRA MA. Ozônio Terapia - Aplicabilidade do Ozônio em Vários Especialidades Odontológicas. International Journal of Advanced Engineering Research and Science, 2020; 7(7): 10.

21. GLÓRIA JCR, et al. Influence of ozonized water on pain, edema, and trismus during impacted third molar surgery: a randomized, triple blind clinical trial. BMC Oral Health., 2020; 20(1): 41.

22. HUTH KC, et al. Effectiveness of ozone against periodontal pathogenic microorganisms. Europe Journal Oral Science, $2011 ; 119(3): 102-204$.

23. LEAL WRS, et al. Controle de infecção bucal utilizando a ozonioterapia. Revista ADM; 2020; 77(5): $267-271$.

24. MARINI S, et al. Oxygen-ozone therapy as adjuvant in the current emergency in SARS-COV-2 infection: a clinical study. by: Promoter of the study: NUOVA F.I.O. (Italian Oxygen-Ozone Federation). J Biol Regul Homeost Agents., 2020; 34(3): 757-766.

25. MARTINS Y, et al. Evaluation and comparison of the effects of hyperbaric oxygen and ozonized oxygen as adjuvant treatments in an experimental osteomyelitis model. Journal Surg Res., 2018; 171(1): 8-61.

26. MINISTÉRIO DA SAÚDE (MS). Portaria $n^{\circ} 702$, de 21 de março de 2018. Disponível em: http://bvsms.saude.gov.br/bvs/saudelegis/gm/2018/prt0702_22_03_2018.html. Acessado em: fevereiro de 2021.

27. NAGAYOSHI M, et al. Antimicrobial effect of ozonated water on bacteria invading dentinal tubules. Journal of endodontics, 2004; 30(11): 778-781.

28. NARDI GM, et al. Evaluation of Salivary Matrix Metalloproteinase (MMP-8) in Periodontal Patients Undergoing NonSurgical Periodontal Therapy and Mouthwash Based on Ozonated Olive Oil: A Randomized Clinical Trial. Int J Environ Res Public Health, 2020; 17(18): 6619.

29. NOGALES CG, et al. Avaliação da ação da água ozonizada frente a bactérias encontradas em casos de periodontite apical secundária persistente. Brazilian Oral Research, 2009; 23(supl. 1): 188.

30. PCHEPIORKA R, et al. Effect of ozone therapy on wound healing in the buccal mucosa of rats. Arch Oral Biol., 2020; 119: 104889.

31. PRESTES LV, et al. Aplicabilidade da ozonioterapia na odontologia: uma revisão de literatura. Arq. ciências saúde UNIPAR, 2020; 24(3): 203-208.

32. SAGLAM E, et al. Evaluation of the effect of topical and systemic ozone application in periodontitis: an experimental study in rats. J Appl Oral Sci., 2019; 28: e20190140.

33. SEIDLER V, et al. Ozone and its usage in general medicine and dentistry - a review article. Prag Med Rep., 2008; 109: 5 e13.

34. SEN S, SEN S. Ozone therapy a new vista in dentistry: integrated review. Med Gas Res., 2020; 10(4): $189-192$.

35. SHEKHAR A, et al. An evaluation of the effect of ozone therapy on tissues surrounding dental implants. International Immunopharmacology., 2021; 96: 107588.

36. SILVA PM, DIETRICH L. Ozonioterapia: capacidade antimicrobiana frente a bactérias da cavidade oral. Revista Psicologia Saúde em Debate, 2018; 4(1): 10.

37. STUBINGER S, et al. The use of ozone in dentristry and maxillofacial surgery: A review. Quintenssencelnt, 2006; 37: 353-359.

38. SUH Y, et al. Clinical utility of ozone therapy in dental and oral medicine. Med Gas Res., 2019; 9(3): 163-167.

39. TASCINI C, et al. Blood ozonization in patients with mild to moderate COVID-19 pneumonia: a single centre experience. Intern Emerg Med., 2021; 16(3): 669-675.

40. VALDENASSI L, et al. Potential mechanisms by which the oxygen-ozone (O2-O3) therapy could contribute to the treatment against the coronavirus COVID-19. Eur Rev Med Pharmacol Sci., 2020; 24(8): 4059-4061. 